\title{
Deployment of a Full- Scope Commercial Nuclear Power Plant Control Room Simulator at the Idaho National Laboratory
}

Ronald Boring Julius Persensky Kenneth Thomas

September 2011

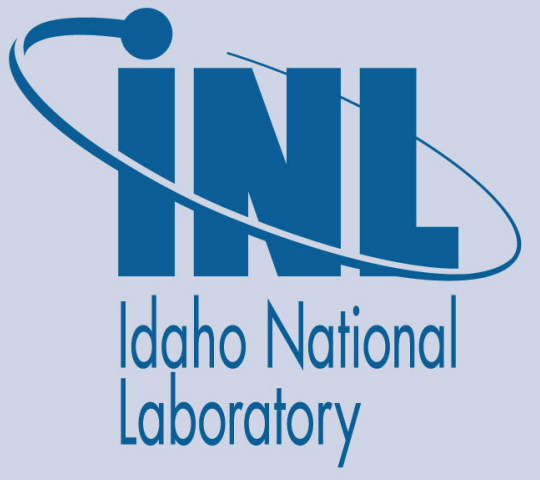

The INL is a U.S. Department of Energy National Laboratory operated by Battelle Energy Alliance 


\section{DISCLAIMER}

This information was prepared as an account of work sponsored by an agency of the U.S. Government. Neither the U.S. Government nor any agency thereof, nor any of their employees, makes any warranty, expressed or implied, or assumes any legal liability or responsibility for the accuracy, completeness, or usefulness, of any information, apparatus, product, or process disclosed, or represents that its use would not infringe privately owned rights. References herein to any specific commercial product, process, or service by trade name, trade mark, manufacturer, or otherwise, does not necessarily constitute or imply its endorsement, recommendation, or favoring by the U.S. Government or any agency thereof. The views and opinions of authors expressed herein do not necessarily state or reflect those of the U.S. Government or any agency thereof. 


\title{
Deployment of a Full-Scope Commercial Nuclear Power Plant Control Room Simulator at the Idaho National Laboratory
}

\author{
Ronald Boring \\ Julius Persensky \\ Kenneth Thomas
}

September 2011

Idaho National Laboratory

Idaho Falls, Idaho 83415

http://www.inl.gov

Prepared under Work Package L-11N060201

Prepared for the

U.S. Department of Energy

Office of Nuclear Energy

Under DOE Idaho Operations Office

Contract DE-AC07-05ID14517 



\section{CONTENTS}

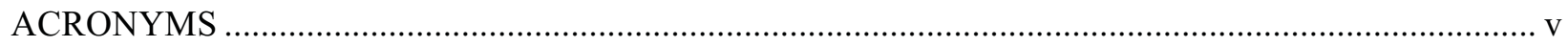

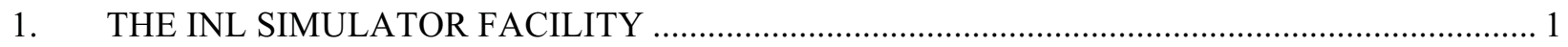

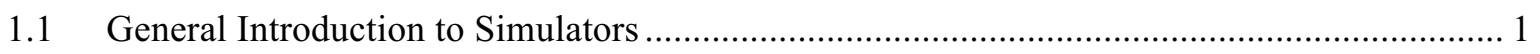

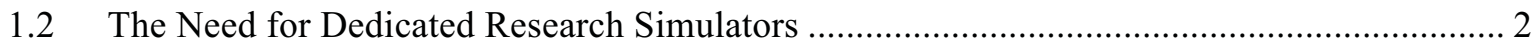

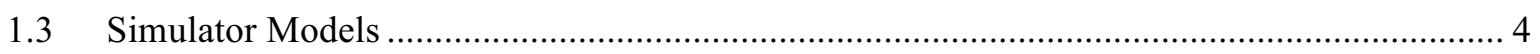

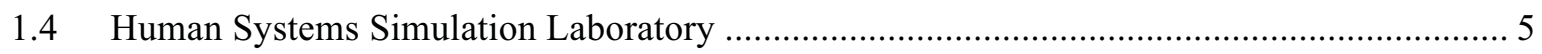

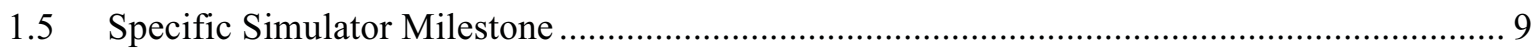

\section{FIGURES}

Figure 1. The different components of a plant simulator ................................................................... 4

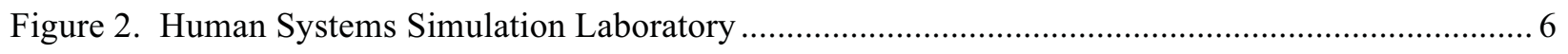

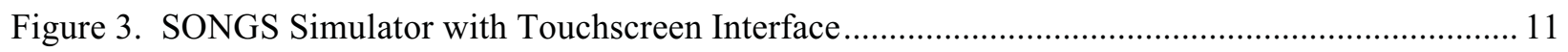




\section{ACRONYMS}

CAES Center for Advanced Energy Studies

CAVE Computer-Aided Virtual Environment

CRADA Cooperative Research and Development Agreement

HSI Human-System Interface

HSSL Human System Simulation Laboratory

I\&C Instrumentation and Control

IAEA International Atomic Energy Agency

INL Idaho National Laboratory

LWRS Light Water Reactor Sustainability

NPPS Nuclear Power Plants

NRC Nuclear Regulatory Commission

SONGS San Onofre Nuclear Generating Station 


\section{THE INL SIMULATOR FACILITY}

\subsection{General Introduction to Simulators}

A simulator is a physical device that replicates the operations of an actual device used in the workplace. Typically, simulators serve to train operators on the proper use of workplace devices, but simulators are also frequently employed in research to evaluate human performance. Simulator technology for domains such as aviation emerged in the 1930s with the invention of the Link Trainer, a mockup plane that allowed pilots in training to learn to manipulate flight controls in a rudimentary manner. ${ }^{1}$ It was not until considerably later - with advances in computing technology - that mathematical systems models and computer generated imagery could be harnessed to create realistic, virtual flight simulations.

A similar course was followed for nuclear power plants (NPPS) - initial, nonoperational hardware mockups of control room panels used by the U.S. nuclear Navy and plant vendors gave way to entire control room simulators with functional control panels that connected with underlying thermal-hydraulic code. Nuclear power plant simulators evolved from being static training representations to interactive, operational systems that could be used to train and test reactor operators' knowledge of plant states and scenarios. An NPP simulator today consists of a computing system to mimic the function of the plant and a physical representation of the control room to allow to monitor simulated plant states and control plant functions.

Historically, by 1973, fully functional simulators had been developed that had all the controls, dials, gauges, lights, switches, and recorders found at the host plants. The early simulators attempted a high degree of physical realism by providing a reasonably faithful replica of the control rooms found at actual plants. Frequent updates to plant control room hardware, due to the changes in technology used at operating plants, meant that the simulator had to be updated and reprogrammed on a frequent basis; making the simulator's replication of the plant control room difficult to maintain. Functionally, the underlying computing system had limited success at achieving realistic scenario progressions, because only a limited number of plant scenarios could be accommodated by the underlying computing hardware. Nonetheless, these early simulators served a vital role in training and licensing crews.

A 2004 report by the International Atomic Energy Agency $^{2}$ (IAEA) highlights the historic development of training simulators. Beginning in the 1970s, computerized control room simulators were put in place at centralized facilities to help train control room operators. These simulators were limited by a lack of fidelity in terms of control panel layouts and underlying thermal-hydraulic code, making them useful for teaching basic plant principles but less useful for plant-specific training. By the 1980s, the fidelity and availability of simulators was greatly increased, and by the 1990s, it became commonplace internationally for each plant to have a high-fidelity plant-specific training simulator. In the U.S., a requirement for training simulators at every plant was introduced so that the NRC could license operators with a high degree of confidence, which also enabled reactor operators to train on unusual or unlikely events. ${ }^{3}$

The IAEA ${ }^{4}$ defines four different types of plant simulators. These include:

- Basic principles simulator - provides a simulation of general concepts relevant to the operation of a plant without providing a faithful mockup of a specific plant

- Full-scope simulator - is a faithful replica of a specific plant control room and its operations 
- Other-than-full-scope control room simulator - closely mimics a plant but deviates from its human-machine interface

- Part-task simulator - only models specific systems and interfaces of a plant.

In practice, the term training simulator is synonymous with a full-scope simulator as would be found at an NPP. All simulator types may be used as part of an effective training regime, but there has been increased emphasis on and requirements for training in full-scope simulators.

Training simulators at NPPs are in high demand. Despite high plant use of training simulators, there remains an ongoing and equally important need to use simulators for understanding operator performance. The need for research on control room crews serves to maintain and enhance the safety at current plants and to document operator interaction with emerging control room technologies. Yet, the availability of training simulators is severely limited, and there remains the inability to reconfigure their use for research purposes. As such, control room simulators have been created to serve the primary purpose of conducting research independent of training. These are research simulators.

\subsection{The Need for Dedicated Research Simulators}

Research can be performed using both training and dedicated research simulators. The differences are centered on the types of studies that can be conducted and the types of data that that can be collected from the studies.

Where the aim is to collect human performance information from actual crews in current control room configurations, the training simulator offers a logical first stop. Participation in simulator research studies affords a unique opportunity to investigate factors affecting crew performance in current control rooms. Practically speaking, over time, such studies may be used to establish new industry best practices and to improve crew preparedness for unusual plant events. From a research perspective, findings from training simulator studies may inform new or improved methods of human performance or human reliability analysis, or be used to develop a more realistic representation of normal crew performance. Such research may also drive recommendations for the implementation of next-generation control room interfaces, based on principles of crew performance in current control rooms.

However, the practical limitations of training simulators for research must be understood:

- Limited availability. Training simulators have as their first priority the training of crews. Research studies may be scheduled as available, but they must not interfere with required training exercises. For this reason, research studies that align closely with training tasks are best suited for training simulators. Crews, trainers, and the simulator facility are limited commodities at the plant, and research studies should complement their primary purpose.

- Simulator inflexibility. The flexibility to manipulate plant parameters and operational situations is limited in the training simulator. For particular research questions related to crew performance, it may be desirable to configure the plant parameters in an unusual way (e.g., multiple simultaneous faults). While this level of control should be available in training simulators, the ease with which such manipulations can be made may be limited by the need to create readily configurable scenarios appropriate to training. 
- Limited data collection. The ability to collect different types of data in the naturalistic setting is restricted. Primarily observational and plant log data may be collected, and advanced data collection techniques such as noted in Tran et al. ${ }^{5}$ are not easily or unobtrusively retrofitted to the training simulator.

- Fixed Human-System Interface (HSI). Training simulators are purpose built to mimic the actual HSI of a specific plant. As such, training simulators are not typically well suited for exploratory studies of novel control room interface elements. Though training simulators may be suitable for implementation of equipment upgrades at the plant (e.g., phasing in new control panels and training crews on them prior to installation in the actual plant control room). They are not, however, generally suited for trying out new equipment.

The above limitations of training simulators for research illustrate the importance of maintaining and championing dedicated research facilities like the Idaho National Laboratory's (INL's) Human System Simulation Laboratory (HSSL), a simulator for control room simulation. Dedicated research simulators are ideal for:

- Scheduling flexibility. Research simulators are generally not in as heavy rotation for use as plant training simulators. Depending, of course, on the number of studies being conducted, it is possible to schedule research simulators for longer periods of time and with greater scheduling flexibility.

- Configuration flexibility. Research simulators offer maximum control over plant parameters and do not have to be limited to a specific plant. In fact, research simulators may be reconfigured to different types of plants, including advanced plants that are still under development. For example, a research simulator may be easily reconfigured to be a pressurized water reactor or a boiling water reactor. Further, a research simulator may be configured to be functionally equivalent to specific plants within those plant types. A research simulator may also be reconfigured in task- or function-specific instrumentation and control (I\&C), such as evaluating operator performance in response to digital alarm systems. It is also possible to couple a research simulator to hard panels that faithfully mimic analog control rooms.

- Data flexibility. Research simulators may allow the collection of observational data similar to those data collected in training simulators. In addition, it is possible to collect data such as physiological measures and eye tracking 5 requiring specialized equipment that is not easily retrofitted to training simulators, as noted.

- Crew flexibility. Reconfigurability makes it possible to study crews from different plants within the same study. The simulator may be configured to match the home plant very closely, or a hybrid approach may be adopted, whereby crews operate on a generic plant that is similar to but not identical to their home plant. For example, studies involving different crews are important for understanding operational culture. ${ }^{6}$

Of course, limitations to using research simulators exist, not the least of which is the feasibility of securing qualified reactor operators to participate in studies. Beyond that, the primary limitation is the generalizability of the results:

- Generalizability of the control room. In a research simulator, the HSI may not be a direct replica of a specific physical plant but rather a functional equivalent. Evidence suggests 
that simulators that are functionally similar will generate comparable results to each other. ${ }^{7}$ However, some features of research simulators can introduce subtle differences between the simulator and the actual plant. Such differences are endemic to research simulators, although measures are being undertaken at the INL to ensure maximum compatibility of the research simulator to actual plant control rooms.

- Generalizability of the crews. In part, differences in operational culture may make it difficult to generalize simulator study results across crews. There are differences in crews due to the nuances of plant design, differences in training, and other factors. It can be difficult to generalize the findings from one plant or crew to another. For this reason, INL is focusing on general principles and findings rather than plant-specific findings for its longer-term research. Of course, beyond general principles, research conducted in support of a specific plant will make maximum use of the crews connected to that plant.

\subsection{Simulator Models}

A plant simulator comprises several layers of systems as depicted in Figure 1. At the heart are system models that interact to create a realistic model of plant behavior, including thermal-hydraulic software modeling using RELAP software, a vendor-specific simulator

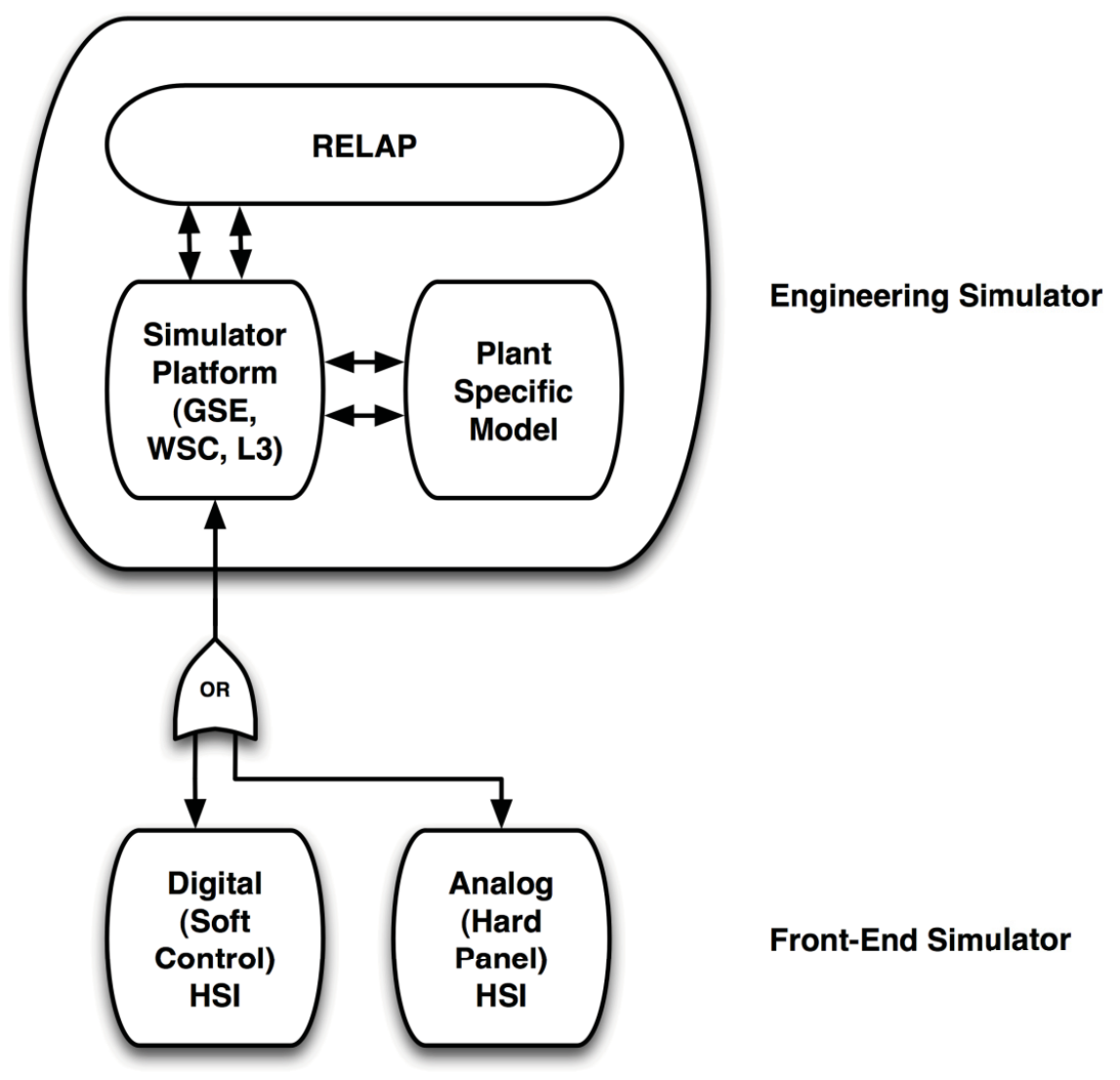

Figure 1. The different components of a plant simulator 
platform (e.g., simulator software development packages by GSE, WSC, and L-3), and a plant-specific model executed on the simulator platform. These models combine to form the back end called the engineering simulator. The engineering simulator interfaces with the front-end simulator, which consists of the control room HSI that the operator uses to understand plant states and control plant functions. The front-end simulator may take many forms such as an analog hard panel system found in typical U.S. training simulators or a digital soft control system found in some foreign plants and research and development simulators. Digital soft control systems may take the form of mimics to analog plant I\&C or may represent advanced I\&C that incorporates features such as overview displays and intelligent trending.

\subsection{Human Systems Simulation Laboratory}

The INL operates the HSSL to conduct research in the design and evaluation of advanced reactor control rooms, integration of intelligent support systems to assist operators, development and assessment of advanced human performance models, and visualizations to assess advanced operational concepts across various infrastructures. This advanced facility consists of a reconfigurable simulator and a virtual reality capability (known as the Computer-Aided Virtual Environment (CAVE) (Figure 2). It supports human factors research, including human-in-theloop performance, HSI, and analog and digital hybrid control displays. It can be applied to the development and evaluation of control systems and displays for complex systems such as existing and advanced NPP control rooms, command and control systems, and advance emergency operations centers.

The HSSL incorporates a reconfigurable control room simulator, which is currently housed in the Center for Advanced Energy Studies (CAES), a joint venture of the DOE and the Idaho University System. The simulator is a platform- and plant-neutral environment intended for fullscope and part-task testing of operator performance in various control room configurations. The simulator is not limited to a particular plant or even simulator architecture. It can support engineering simulator platforms from multiple vendors using digital interfaces. Due to its ability to be reconfigured, it is possible to switch the HSI — not just to digital panels but also to different control modalities such as those using greater plant automation or intelligent alarm filtering.

The simulator currently includes three operator workstations, each capable of driving up to eight 30 -inch monitors. The size and number of monitors varies depending on the particular front-end simulator deployed for a simulator study. These operator workstations would typically be used for the shift supervisor or senior reactor operator, reactor operator, and assistant reactor operator in current US NPPs. In addition to the three workstations, information can be shared between the workstations and further displayed on a large-screen overview display or a panel mimic. An 82inch high-definition display is commonly used for the overview display. One configuration of the INL simulator can be seen in the figure below. 


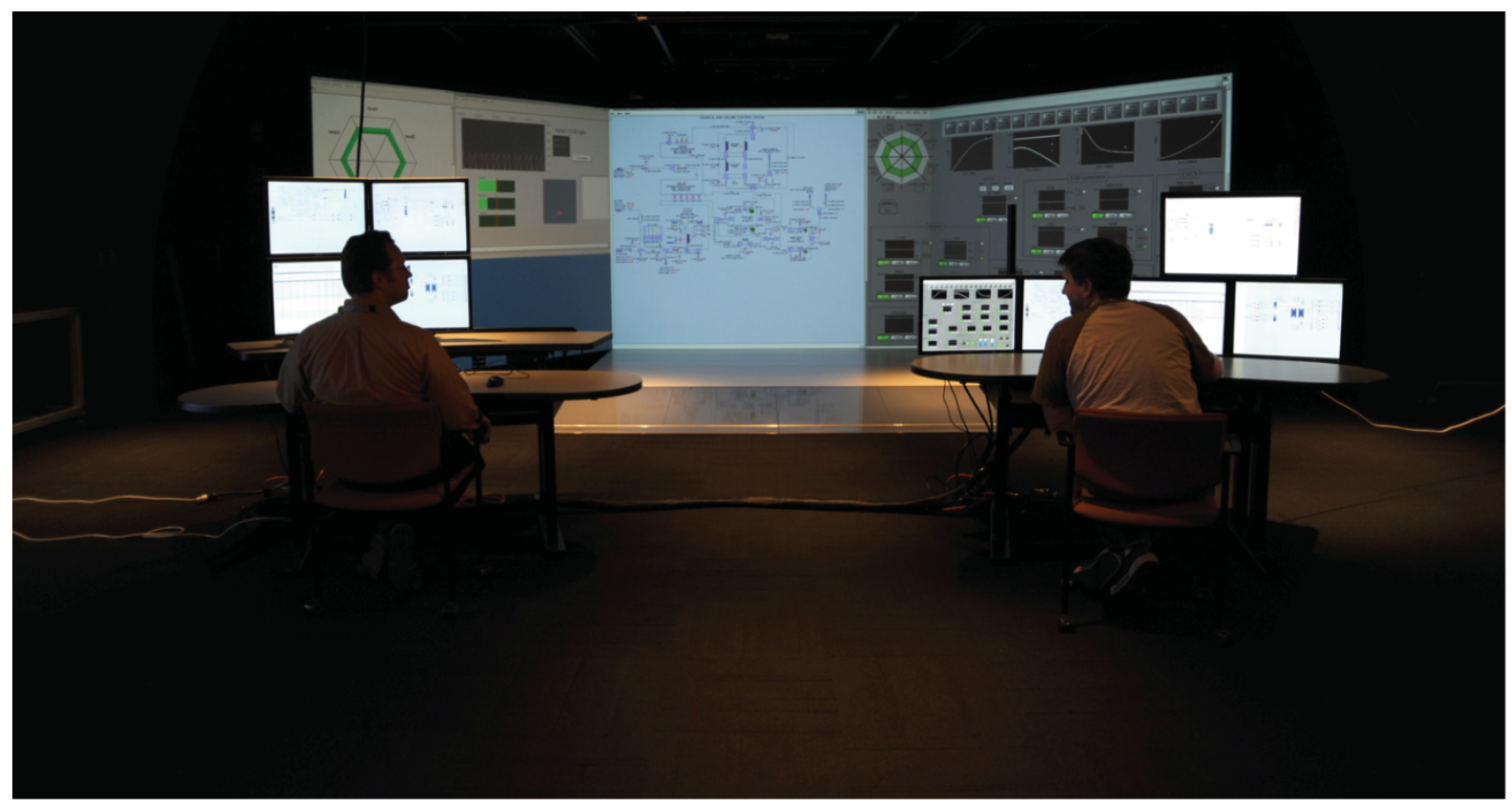

Figure 2. Human Systems Simulation Laboratory

To complement the individual computer workstations, the INL simulator shares space with a virtual reality cave. The HSSL has the ability to interface with each of the three walls of the cave, displaying any information for the workstations on a wall of the CAVE. One of the many features that this cave system affords is the ability to unfold the side walls to a full length 30 -foot large display. This configuration allows for a very large overview display area or a realistic control room panel replica.

Also, there is the capability to record audio and video for later review, and for coding of behavioral data. Physiological data is collected from a system consisting of a transmitter and receiver that hooks into the electrodes used to gather respiration, galvanic skin response, and heart rate data. An eye-tracking system, consisting of two infrared cameras, is available on each operator workstation to provide data on gaze, blinking, and areas of concentration.

The HSSL can be used in studying human performance in a near realistic operational context for advanced NPP control room design. The facility is equally suitable for human performance measurement in other NPP control centers such as an outage control center, a centralized online monitoring center, and emergency response facilities. Assessment of human performance in a naturalistic setting includes studies in a range of the following focus areas:

- Human-system performance relationships between the reliability of the operator, the time available to perform an action, and the influence of the performance characteristics of the plant or system on the task.

- Usability of the human systems interface includes effectiveness, efficiency, safety, and reliability with which an operator can perform specific tasks in a specific operational 
context (normal or emergency). This includes the effect on human performance with different technologies and different human systems interface configurations.

- Human performance expressed as physical, cognitive workload, under different operational conditions, including the following:

- Monitoring

- Human error, human reliability, and human error mechanisms

- Task completion (accuracy, speed, tolerance, and variability)

- Problem diagnosis

- Decision making

- Following procedure

- Response times

- Situational awareness with a given human systems interface and control configuration under different operational conditions.

- Crew communication effectiveness with given technologies under different operational conditions.

- Human performance with different staffing configurations and a given control room configuration.

HSSL provides the simulation and visualization capabilities needed for pilot projects involving development and evaluation of new technologies for the main control room and other control centers. As such, the new technologies can first be staged in the HSSL for proof-ofconcept prior to demonstration at host utility NPPs. The HSSL facilities can be configured in a variety of settings according to the functional context of each type of plant control center.

To meet the needs of each type of control center, the HSSL will require new capabilities and upgrades as the research program progresses. Over time, this will result in an HSSL of highly complex and sophisticated features that will enable realistic modeling of the tasks and functions required of the various plant control centers. It is envisioned that HSSL will be the leading facility in the United States for validation of new operational concepts and technologies for the light water reactor fleet, thereby ensuring that nuclear plant modernization of II\&C systems is based on demonstrated and validated scientific principles.

One challenge associated with collecting data in NPP control room simulators is the issue of how to measure operator performance. Experimental results must have relevance to real world control rooms. Many of the methods currently employed in studies investigating human performance in the nuclear industry are subjective and qualitative. For example, many studies have employed the use of expert observation to collect data on human performance. While expert observation can provide valuable information on operator performance, it is desirable to use methods that are objective and quantifiable to measure human performance in simulator studies.

The INL staff at the simulation facility use a combination of methods focusing on the collection of objective performance data logged by the simulation software (including tracking plant parameters, alarms, operator control actions, and operator response times) and the continuous collection of physiological data that are known to correlate with human performance 
issues like mental workload, situation awareness, and fatigue. The specific data collection methods the INL simulation facility employees are:

1. Eye tracker - researchers in the INL simulation facility use eye tracking systems to measure situation awareness and workload. Workload is measured via blink rate and blink duration. Both blink rate and blink duration decrease with increasing mental workload. ${ }^{8,9}$ Eye tracking is also used to measure situation awareness by assessing gaze patterns. Situation awareness can be assessed by measuring an operator's anticipation of an event by focusing his gaze in the direction where relevant information will be displayed. ${ }^{10}$ Situation awareness can also be measured by measuring an operator's gaze pattern and duration of fixation. ${ }^{11}$

2. Electrocardiogram - researchers use electrocardiogram to measure heart rate and heart rate variability. Previous research shows that heart rate increases as mental workload increases. In addition to heart rate, heart rate variability has been shown to indicate changes in mental workload. ${ }^{12}$

3. Respiration - researchers use respiration cycle time to measure cognitive workload. Previous research has shown that cycle time decreases as cognitive workload increases.9

4. Galvanic skin response-researchers in the INL simulation facility use mean galvanic skin response to measure cognitive load. Preliminary research has shown that mean galvanic skin response increases with increasing cognitive load. ${ }^{13}$

5. Plant performance - researchers track plant parameters (e.g., pressurizer pressure, flow, and reactor power) and compare them to the ideal parameter for a given simulation scenario. This measure allows for the quantification of plant performance, which combines human performance and system performance into one measure.

6. Operator and crew performance-operator and crew performance are measured with response times and errors. Response times are defined as time to detect malfunctions, time to diagnose malfunctions, time to initiate procedures, and time to complete a scenario. Errors are defined in the context of the current scenario. Definitions of errors could include incorrect control action, deviation from an ideal sequence of actions, omission of a procedure step, etc. In addition, subjective measures of performance as assessed by subject matter experts using observation techniques are combined with the objective measures to provide a complete picture of operator and crew performance.

7. Self-report techniques - workload and situation awareness are also measured subjectively using self-report techniques. Workload is assessed using the NASA TLX, ${ }^{13}$ while situation awareness is measured with a survey developed by INL staff. Self-report techniques can be compared to objective measures of workload and situation awareness to determine the degree to which they correlate.

These data collection methods are used to assess the operator response to a given control room configuration or situation. The objective of the alarm research project is specifically to look at operator performance in the face of novel alarm technologies. The INL simulation facility includes a unique and extensive suite of performance measures that allows a thorough evaluation and validation of alarm system HSIs. 


\subsection{Specific Simulator Milestone}

The INL acquired the full-scope simulator for a Westinghouse 4-loop commercial pressurized water reactor (plant name omitted due to confidentiality agreements). The simulator software consists of the full plant model software and accompanying displays that mimic the analog I\&C of an actual plant control room. The full-scope simulator was installed in the HSSL, with the displays representing a realistic control room configuration. The simulator software was installed on a rack-mounted workstation, which is capable or driving eight video displays. Each workstation was equipped with four twenty-one inch flat panel LCD monitors that are used to display the plant I\&C.

INL's unique suite of human performance monitoring tools was calibrated to the simulator configuration to enable operator-in-the-loop testing. The equipment used to monitor operator performance in the control room simulator includes:

- The faceLABTM eye-tracking system, consisting of a Windows laptop with two infrared camera pods available on each operator workstation to provide data on gaze (eye tracking), blinking, and areas of concentration.

- An additional workstation is designated for the recording of audio and video for review, and coding of behavioral data; it is also used for the recording of physiological data collected from the BioPackTM, a system consisting of a transmitter and receiver that hooks into the electrodes used to gather respiration, galvanic skin response, and heart rate data via electro-cardiogram.

- Four Sony EVI-D70 Cameras are positioned around the operators, providing over the shoulder views or environment overviews as desired. Using lightweight low profile camera stands provides quick setup and reconfigurable functionality. Coupling the easy to move physical locations with the remote zoom and panning feature enables getting desired views to be relatively easy.

The acquisition and installation of the full-scope simulator for use at the HSSL represents the successful completion of a Department of Energy Level 3 Milestone L-11IN060301 in Fiscal Year 2011. The acquisition of the simulator allowed the INL to familiarize itself with the operation and controls of a plant simulator and optimize the human performance monitoring tools for use in simulator studies.

\subsection{Additional Simulator Acquisition}

The Westinghouse 4-loop pressurized water reactor simulator described in Section 1.5 successfully completed the milestone and enabled the INL to configure its HSSL in a manner that faithfully replicated plant I\&C and allowed human performance data collection. However, there are limitations to the currently installed system. Because the plant modeled in the simulator is not an active participant in the LWRS Program, the practical use of the simulator for control room and alarm system upgrades is limited. In order to align the simulator buildout with LWRS programmatic research interests, the INL is acquiring an additional full-scope simulator for use in the HSSL. 
INL staff members are currently working with the San Onofre Nuclear Generating Station (SONGS), a Southern California Edison property, to assist them in upgrading their main control room. SONGS consists of two Combustion Engineering two-loop pressurized water reactors with two accompanying control rooms. Due to the unique geography of the setting, the SONGS control rooms are small sized in comparison to other control rooms in the commercial nuclear industry. Size has presented a number of constraints to the upgrade and has made it necessary for SONGS to look beyond standard vendor offerings in digitizing their control room. The INL is assisting SONGS through a Cooperative Research and Development Agreement (CRADA), in which INL develops and tests digital control room upgrade solutions that can be applied toward creating a design specification for the vendor. In particular, SONGS is interested in replacing its alarm system - a series of lightbox annunciator tiles distributed across panels in the control room. To this end, INL is reviewing applicable replacement technologies. A major research question that isn't being addressed by vendors is the tradeoffs inherent with switching from current annunciator panels - in which the operators gain a system overview - with digital alarm lists. SONGS wishes to work with INL to determine an optimal alarm solution, whether it proves to be a mimic of current analog annunciators, a complete replacement of the annunciators with digital alarm lists, or a hybrid solution. The results of this collaboration will be disseminated beyond SONGS and serve to answer an industry need for the most effective way to upgrade alarms while maintaining or exceeding current safety levels.

Pending successful signing of a three-party non-disclosure agreement, SONGS will provide the INL with a copy of its full-scope simulator software developed by L-3 Communications. The L-3 software is capable of running on a single multiprocessor Windows computer and includes mimic displays corresponding to every instrument and control in the physical plant, similar to the simulator currently in the HSSL. The L-3 software is a plant-specific model built on top of L-3's proprietary Orchid simulator software, which is layered on top of RELAP thermal-hydraulic code. The controls are displayed on screens, each screen representing a panel of the physical control room. The simulator software includes L-3's Orchid Development Suite, which allows customization of the control screens. The L-3 platform can also be interfaced with other frontend HSI software like Halden Reactor Project's ProcSee, allowing the INL to develop advanced displays independent of the display technology built into the simulator software.

While the L-3 simulator software is a full-scope environment, additional software tools will be employed in Fiscal Year 2012. The SONGS plant computer by Scientech and Westinghouse's Ovation software will be deployed to allow integration with existing digital displays in the control room and seamless integration with the upgrade path planned at the plant. In addition, SONGS has developed an interface that allows the plant controls to be accessed via touchscreen (see Figure 3). INL plans to implement this touchscreen technology in the HSSL with the acquisition of compatible hardware in 2012. 


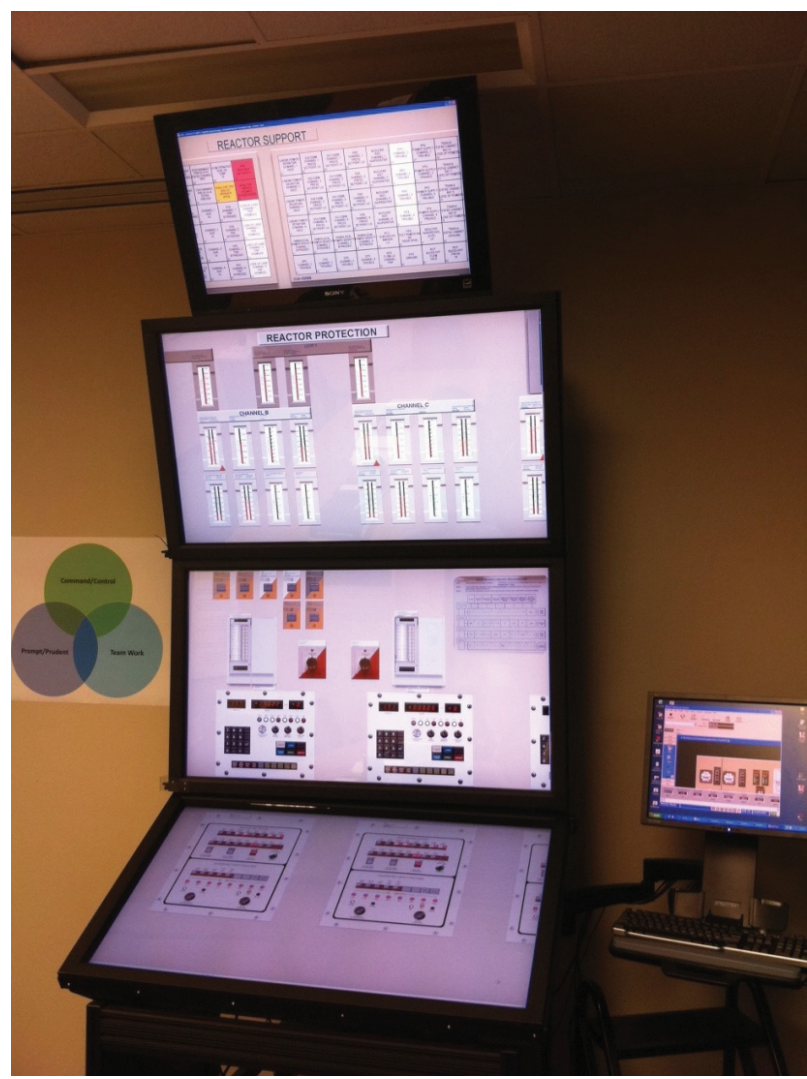

Figure 3. SONGS Simulator with Touchscreen Interface

The acquisition of the SONGS full-scope simulator will allow the INL to familiarize itself with the operation and controls of the SONGS plant and to begin designing alternative interface elements - in particular alarm panel replacements - early in Fiscal Year 2012. Upon the design of such replacement interface elements, the INL will serve as the test facility to verify and validate the design concepts. The results of planned operator-in-the-loop studies at the INL's HSSL will help SONGS to complete its alarm system upgrade in the plant as well as provide new insights into alarm system design that can serve as a benchmark for regulatory guidelines and industry deployment.

1. Robertson Museum and Science Center, 2000, "The Link Flight Trainer: A Historic Mechanical Engineering Landmark," American Society of Mechanical Engineers, New York.

2. International Atomic Energy Agency (IAEA), 2004, "Use of Control Room Simulators for Training of Nuclear Power Plant Personnel," IAEA-TECDOC-1411, IAEA, Vienna, Austria.

3. U. S. Nuclear Regulatory Commission (NRC), 2001, "Nuclear Power Plant Simulation Facilities for Use in Operator Training and License Examinations, Rev. 3," Regulatory Guide 1.149, NRC, Washington, D. C. 
4. International Atomic Energy Agency (IAEA), 2003, "Means of Evaluating and Improving the Effectiveness of Training of Nuclear Power Plant Personnel," IAEA-TECDOC-1358, IAEA, Vienna, Austria.

5. Tran, T. Q., R. L. Boring, D. D. Dudenhoeffer, B. P. Hallbert, M. D. Keller, and T. M. Anderson, 2007, "Advantages and Disadvantages of Physiological Assessment for Next Generation Control Room Design," Proceedings of the Joint 8th IEEE Conference on Human Factors and Power Plants, Monterey, CA.

6. Heimdal, J., 2007, “Operational Culture Literature Review: Extended Summary,” HWR-901, OECD Halden Reactor Project, Halden, Norway.

7. Stanton, N., 1996, "Simulators: A Review of Research and Practice," Human Factors in Nuclear Safety, N. Stanton (ed.), Taylor and Francis, London, England.

8. Brookings, J. B., G. F. Wilson, and C. R. Swain, 1996, "Psychophysiological responses to changes in workload during simulated air traffic control." Biological Psychology, 42, 361-377.

9. Veltman, J. A., and A. W. Gaillard, 1988, "Physiological workload reactions to increasing levels of task difficulty," Ergonomics, 41, 656-669.

10. Hauland, G., 2003, "Measuring team situation awareness by means of eye movement data," Proceedings of HCI International 200, Mahwah, NJ: Lawrence Erlbaum Associates, 3, 230-234.

11. Hauland, G., 2008, "Measuring Individual and Team Situation Awareness During Planning Tasks in Training of En Route Air Traffic Control," The International Journal of Aviation Psychology, $18(3), 290-304$.

12. Hjortskov, N., et al., 2004, "The effect of mental stress on heart rate variability and blood pressure during computer work," European Journal of Applied Physiology, 92, 84-89.

13. Shi, Y., N. Ruiz, R. Taib, E. Choi, and F. Chen, 2007, "Galvanic Skin Response (GSR) as an Index of Cognitive Load," CHI '07 Extended Abstracts on Human Factors in Computing Systems, ACM, New York, NY, 2651-2656. 